Company, Stollwerk and Co., of Cologne, in 1900-5 at the house in Georgstrasse. He says that there were automatic chocolate machines, automatic music machines, electric pianos, weighing machines, the $x$-ray apparatus, automatic peasant bands, and a peepshow of the Frenchman Lumière. In the cellar of the house a cinematograph apparatus functioned from time to time. Although Herr K. M. could not confirm the year 1896, Herr B. S. produced the answer to the key question. He could say for certain that he had seen the $x$-ray apparatus in 1896 because he was married that year, and he had gone to the showplace with his new brother-in-law.

Further confirmation of the date 1896 came from a 78-year-old reader, Herr K. K., who became a soldier in 1897 and was quite definite that he went to the automaton show the year before. Dr. B. reported that in 1896 he already owned an $x$-ray apparatus in his practice, purchased through the firm of Nicolai, Leinstrasse, from Reiniger, Gebhard, and Schall. Herr O. R. also reported that a doctor in Gehrden owned an $x$-ray apparatus in 1896.

It seems, therefore, that Hanover and the show business were right up to date in March, 1896.

$$
\text { REFERENCES }
$$

1 British Medical Journal, 1954, 2, 469.

2 British Medical Journ

Early History of the Roentgen Rays, 1933. John Bale. Sons and Danielsson Ltd.

\section{FLUORIDATION OF DOMESTIC WATER SUPPLIES}

The Board of Faculty of Dental Surgery of the Royal College of Surgeons of England was asked some time ago by the Minister of Health to consider the question of the fluoridation of domestic water supplies. The following report was therefore drawn up, and last week it was accepted and approved by the Board of Faculty of Dental Surgery and by the council of the Royal College of Surgeons. The Board is satisfied that the incidence of dental caries is much less among children and adults who have spent the whole of their pre-natal and post-natal life in areas where the drinking water naturally contains fluoride at a level of one part per million or more than among those in areas where the water is practically free from fluoride.

In 1945 the fluoridation of domestic water supplies for reducing the incidence of dental caries was started in certain selected communities in the United States of America and in one in Canada. Eight of these communities in which fluoridation was started from 1945-48 have been used as study centres. The results obtained each year have been compared with the base-line data, and in some centres, as an additional control, dental examinations have been undertaken in adjoining and comparable communities.

The evidence to date shows a reduction in dental caries incidence of $40 \%$ to $50 \%$ in children of the youngest age groups, which is comparable to what is observed in areas where the water has naturally a fluoride content of one part per million or more. In the older age groups the teeth have not been subjected to fluoridation during all their formative period, and the reduction is not as yet so marked. There is nothing to suggest that a water naturally containing fluoride has properties different from those to which fluoride has been added.

In a temperate climate, with a population of adequate nutritional standard, fluoride at a concentration of 1-1.5 parts per million as fluorine in the water produces an occasional white fleck on the enamel, but this cannot be detected without expert dental examination, and is found in only about $10 \%$ of children. The appearance of the teeth is excellent.

There is no scientific evidence of toxicity or of harmful effects in districts with the water supply fluoridated at this level.

The Board considers that there is very strong evidence in support of fluoridation, and welcomes the proposal that this procedure should be adopted in the first place in some selected districts that can be used as study centres.

\section{Correspondence}

Because of the present high cost of producing the Journal, and the great pressure on our space, correspondents are asked to keep their letters short.

\section{Renal Biopsy}

SIR,-Your leading article on renal biopsy (Journal, December 18,1954 , p. 1468) seems to us to imply that our technique of percutaneous biopsy of the kidney in the prone position is a simple matter which can be done by anybody. This is not so. We believe that indiscriminate use of the technique by untrained people will certainly lead to accidents. We feel that for the present the operation should be done only by those physicians or surgeons who are going to use the technique frequently as part of a programme for the study of patients with renal or related diseases.

Since our report ${ }^{1}$ in May of last year we have done a further 150 biopsies, making in all a total of just under 200 biopsies to date. We have encountered no serious complications with our technique and have extracted adequate tissue for histological diagnosis in over $95 \%$ of our attempts at biopsy. The dangers of renal biopsy are retroperitoneal haemorrhage, severe laceration of the kidney, renal infarct, anuria, and spread of infection. We have been fortunate in that our only complications so far have been transitory renal colic in three patients, mild loin pain in six, and a sharp haemorrhage into the bladder in an old gentleman with severe calcific atherosclerosis.

In order to secure the safety of the patient, particular pains have been taken in the selection of patients, and meticulous attention has been given to their pre- and postoperative care. At present our contraindications for doing a biopsy are: an uncooperative patient, individuals with a bleeding tendency, patients with one kidney, and patients with oliguria whose non-protein nitrogen is above $100 \mathrm{mg}$. per $100 \mathrm{ml}$. of blood and rising. We do not advise a biopsy on patients who have severe calcific atherosclerosis, a perinephric abscess, hydro- or pyonephrosis, renal neoplasm. or large cysts. Although $\mathrm{Cazal}^{2}$ has done a few biopsies on patients with renal neoplasm, we believe that the danger of spreading neoplastic cells along the needle track is too likely to warrant biopsy.

The hazards of kidney biopsy have been overcome by accurate localization of the kidney with intravenous pyelograms and the exploring needle, by the thin Franklin VimSilverman needle, which secures a small core of renal tissue without aspiration, and by the use of the sandbag in the prone position, which ensures post-biopsy haemostasis. Biopsy of the kidney is more accurate than any other method in making an exact diagnosis. There is no need to labour this point, but it must be obvious that, as time goes on, biopsy of the kidney will become more and more valuable as new therapeutic measures are found to combat each of the many disease processes which involve the kidney. We find that renal biopsy is a more accurate method than culture of the urine or blood in determining exactly the type of organisms which are responsible for infection within the kidney, and we have been using it to select patients with nephrotic syndrome for therapy with steroids. Besides its clinical value in diagnosis, prognosis, and therapy, it is a most valuable tool for studying the natural history of diseases of the kidney.

We have already trained a number of British physicians to do biopsies of the kidney in the prone position, and we look forward, as you do, to reports on its usefulness.-I am, etc.,

Chicago, 12, U.S.A.

ROBERT M. KARK.

REFERENCES

1 Kark, R. M., and Muehrcke, R. C., Lancet, 1954, 1, 1047.

2 La Ponction-biopsie du Foie, 1949. Vigot, Paris 